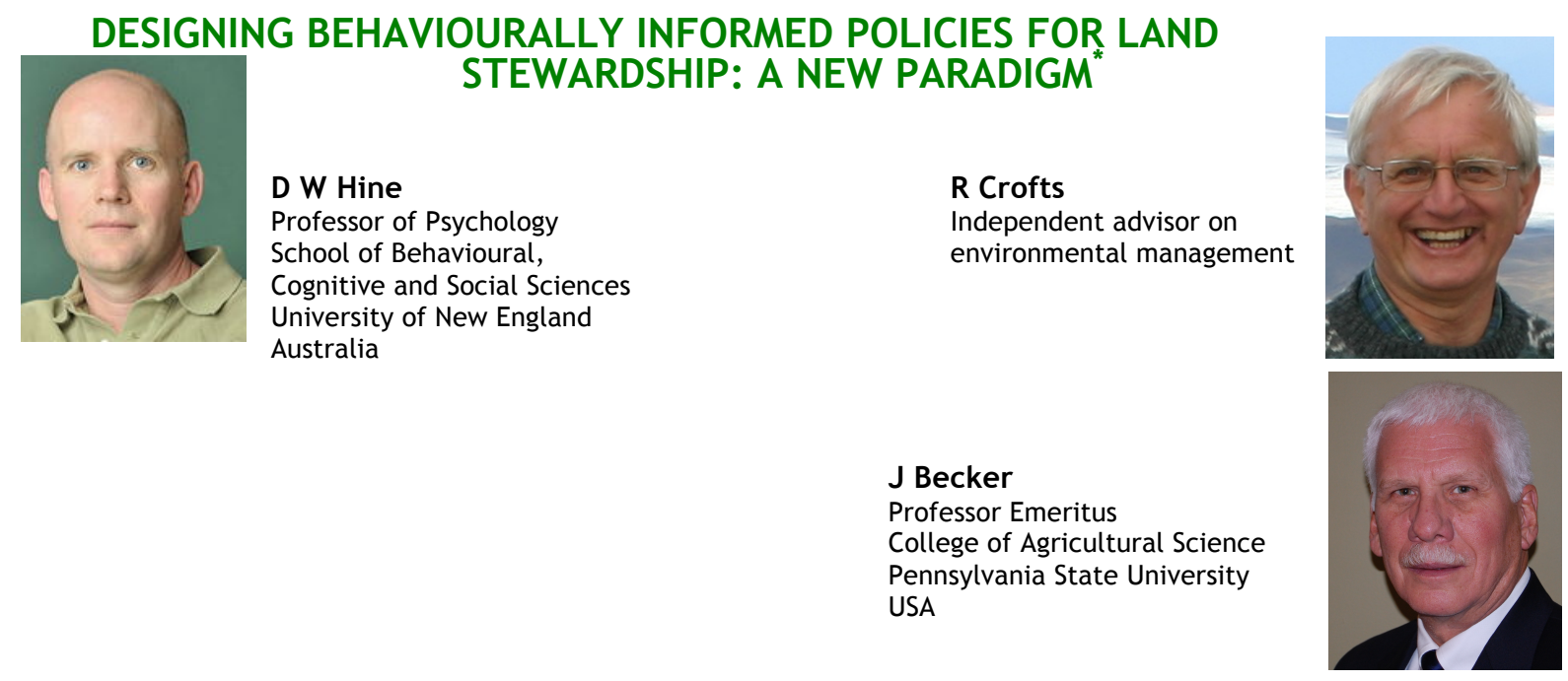

This paper argues the case for a new approach to the stewardship of land resources that uses behavioural science theory to support the design and application of policies that facilitate changes in behaviour by those who develop policy and the farmers who implement it. Current approaches have: focused on legally-based expert system; and have been devised by national and international bureaucracies with little or no knowledge of how land owners and managers are motivated, and how they think, behave and operate as stewards of their natural resources. A review of current approaches from the social scientific literature is provided, with a particular focus on principles from social psychology. This is followed by an examination of how these principles can be applied to influence behaviour related to land restoration and soil conservation. Examples of the problems with traditional approaches and the evolution of new approaches with full engagement of farmers as the delivery agents are provided from within the European Union, Iceland and Scotland. In the light of these examples and emerging thinking in other parts of the world, the paper sets out the basis for a new approach based on behavioural science theory and application, reinforcing the arguments already made in the literature for a social license for farming.

\title{
Introduction
}

This paper argues the case for new approaches and mechanisms for improving land stewardship in the light of the failures of more traditional approaches, and the continuing degradation of the global soil resource at a time when the demands for increased food production are continuing to rise rapidly. First, we review the present state of play around the world on soil stewardship, note the changing influences on land use and soil productivity, and identify the main approaches to land stewardship. Second, we provide assessments of the traditional legal and social science approaches used to stimulate responsible land stewardship. Third, we evaluate new perspectives from the behavioural sciences; specifically those based on behaviour change models that seek to induce improved environmental behaviour by those engaged in land stewardship. Fourth, we ground our assessment with three practical examples from Europe; specifically, mechanisms which seek to reduce conflict between nature-based approaches and farming activities. Finally - and based on our assessments of traditional methods, new approaches and practical examples - we set out a new paradigm for land stewardship comprising seven key ingredients.

\section{The current state of play}

Several recent reviews of the literature on soil loss and soil degradation indicate that there is a continuing problem of the decline of this natural resource. ${ }^{1}$ For example, globally, soil erosion and degradation is evident

\footnotetext{
* This paper arose from the authors meeting at the conference Soils: How do you Create an Enabling Environment, jointly organised by the Icelandic Soil Conservation Service and the University of New England, Australia, July 2012.
} 
on 20 per cent of cultivated land, 30 per cent of forests, and 10 per cent of grasslands. Most (78\%) of the soil loss and degradation occurs in the Earth's humid regions. Soil loss remains greater than the replenishment rate by 10 per cent in the US, and between 30 and 40 per cent in India and China. ${ }^{2}$ The resulting loss of productive capacity can be reversed, in part, with the application of artificial fertilizers. Pests on crops can be controlled through chemical treatments, but these treatments often have negative side effects, such as affecting the genetic integrity of wild plants. In addition, there is widespread public antipathy to Genetically Modified Organisms (GMOs), ${ }^{3}$ although GMOs have been used by farmers throughout the world. As a result of soil loss and the use of pesticides and artificial fertilizers, there are significant downstream effects on the functioning of ecosystems and the quality of water, along with increases in flooding. Overall, soil loss and degradation has been estimated to directly affect 1.5 billion people, with damage costs approximately US\$400 billion per annum. $^{4}$

Without question, soil loss and degradation poses a significant challenge to both policy makers and farmers. From policy analyses and observations carried out by the authors of this paper, there seem to be three main factors contributing to the continuing problem of soil degradation. First are the protectionist and negative attitudes of key stakeholders toward change from traditional land management ideas and practices. Farmers, and other landholders and managers, aided by farmers' unions and farmers' ministers and ministries, frequently take the line that 'we are food producers and have been doing so for centuries so do not tell us what to do as we know'.

Second, in many parts of the world, the farming sector is characterised by outmoded policies and instruments. For example, there are many subsidies for production support despite strictures of the World Trade Organisation (WTO); such as subsidies for oil seed rape in the European Union (EU) and protection of US sugar growers from imported sugar. ${ }^{5}$ Quotas for the production of goods also still exist; even though it is clear that quotas do not work given there are too many exceptionality deals. Many market mechanisms that have been used in an attempt to intervene to improve land management practices appear to be worse than efforts undertaken as a result of the unregulated market. For example, interventions in the market have led to such as problems as excess production of food - commonly known as food mountains - and excess production of wine commonly known as wine lakes - in the EU. Many institutional mechanisms, such as the Single Farm Payments system of the EU Common Agricultural Policy, provide financial support to farmers without establishing environmental conditionality, thus potentially generating perverse incentive structures that reinforce unsustainable activities.

Third, land stewardship tends to be approached as a single issue of greater productivity by farmers and those institutions supporting traditional farming rather than in an integrated manner with environmental sustainability in mind. There is, for example, an over-focus by food ministers in the western world on food security, which is now appearing under the guise of securing food supply in the face of global climate change. The increasing world population, dietary changes in emerging countries, and the demands of consumers in postindustrialised nations for all-year-produce, all exacerbate the problem of a single-issue approach. ${ }^{6}$

Calls for more regulatory approaches and a formal legal basis have been made. For example, Boer and Hannam argue the case for a global protocol for sustainable use of soil. ${ }^{7}$ A tight regulatory approach has been proposed in the EU as a basis for a formal directive on soils, ${ }^{8}$ although there has been no political agreement to its

\footnotetext{
1 H Bigas, G I Gudbrandsson, L Montanarella and A Arnalds (eds), Soils, Society and Global Change: Proceedings of the International Forum Celebrating the Centenary of Conservation and Restoration of Soil and Vegetation in Iceland (European Commission, Luxemburg, 2009) <http://www.land.is/english/images/pdf-documents/eur23784.pdf>; FAO, 'World Reference Base for Soil Resources 2006: A Framework for International Classification, Correlation and Communication' (World Soil Resources Reports, 2006) <ftp://ftp.fao.org/agl/agll/docs/wsrr103e.pdf>; Proceedings of the International Workshop on Strategies, Science and Law for the Conservation of the World Soil Resources (Selfoss, Iceland, September 1418, 2005) <http://www.land.is/english/images/pdf-documents/Rit-LBHI-4-lowres.pdf>.

2 Ibid.

3 S Bonny, 'Why are Most Europeans Opposed to GMOs? Factors Explaining Rejection in France and Europe' (2003) 6(1) Electronic Journal of Biotechnology.

4 FAO, above $\mathrm{n} 1$.

${ }^{5}$ Peter Shelton, 'The Hidden Costs of US and EU Farm subsidies' on IFPRI Blog, International Food Policy Research Institute (1 May 2013) <www.ifpri.org/blog/hidden-costs-us-and-eu-farm-subsidies>.

6 John Parker, 'The 9 Billion-People Question’ Economist (London), 26 February 2011.

7 I Hannam and B Boer, Drafting Legislation for Sustainable Soils: A Guide. (Cambridge, England: IUCN, 2004).

8 European Union, 'Proposal for a Soil Framework Directive' (COM 232, Brussels, European Union, 2006).
} 
introduction. However, traditional regulatory measures are increasingly being criticised for high enforcement and compliance costs and for the adversarial relationships they engendered; ${ }^{9}$ they are, at best, only partially successful because they are constructed in a dirigiste manner with insufficient input from those who will deliver the practice on the ground; they do not adequately account for the motivation of those owning and managing land and how they react to externalities, such as the market, regulation and policy. That is, too often, systems have been devised and implemented in a top-down fashion. Such systems do not take into account that the perspectives of delivery agents and regulatory agents will, inevitably, be rather different; often they diverge. The consequence is that delivery agents are, often, disenfranched throughout the process, despite the fact that they have a legitimate interest as resource owners and have the ability to manipulate what happens on the ground - unless there is much scrutiny from regulatory agents, which is rarely the case because of the resourceintensive nature of scrutiny and enforcement.

As a result of these insights into the shortcomings of traditional approaches, there is now more interest in using behavioural science to understand how behaviourally-informed policy and regulation would differ from the traditional approaches, and on how such policies and regulations would improve land stewardship. This conclusion is supported by examination of the literature ${ }^{10}$ and evidence from reviews of international deliberations, ${ }^{11}$ as well as schemes - such as Landcare ${ }^{12}$ - that have a greater reliance on an informed contractual relationship in which the regulatory agency and farmers work together to resolve a natural resource issue. ${ }^{13}$ Although such interest in the use of behavioural science seems promising, a better understanding of how compliance is affected by implementing collaborative and voluntary programs for environmental goals is needed. There has, therefore, been a substantial growth in the topic by political scientists and public administrators over the past decade, with policy makers and researchers focusing their attention on developing and evaluating cooperative and voluntary alternatives for achieving environmental goals.

\section{Traditional legal approaches to encourage responsible soil management}

In summary, the legal approach is based on an implied contract between society (and its constituent communities) and the government. It is usually implemented through sets of command and control measures in the common form of regulations, with the authorised agency setting standards for the regulated community to follow; ${ }^{14}$ failure to comply results in punitive fines or other punishments. The regulatory approach can also employ incentives or disincentives including taxes, grants, subsidies or rewards, and other market-based incentives, to bring about desired behaviour change. ${ }^{15}$ Scrutiny of adherence to regulations allows the regulatory authorities to identify undesirable behaviour and to consider what changes are needed to the system to bring about socially desirable behaviour. ${ }^{16}$

For the traditional legal approach to work effectively, the following question needs to have been answered from the outset: Is the regulatory objective to gain compliance with regulatory directives (as in the British system) or is it to gain effective deterrence of undesirable behaviour and the resulting outcomes it would cause (as in the US system) $?^{17}$ Regulations are generally viewed as good if they are: based on legislative authority; are accountable; apply fair, open and accessible procedures; employ regulators with required expertise; meet the defined objectives; and are efficient in their operation.

Measuring the effectiveness of regulations is necessary. A simple way would be to ask if the desired change in behaviour occurred. Compliance at the 90 per cent level is often achievable at reasonable cost, but total

9 M. Potoski and A. Prakash, Covenant and Weak Swords: ISO 14001 and Facilities' Environmental Performance, 24 J. of Policy Analysis and Management(2007) 745-769.

${ }^{10} \mathrm{~J}$ Williams and P Martin, Defending the social licence of farming (Melbourne, CSIRO, 2011).

${ }^{11}$ Bigas et al, above $\mathrm{n} 1$.

${ }^{12}$ D Catacutan et al, Landcare: Local Action - Global Progress (Nairobi, World Agroforestry Centre, 2009).

${ }^{13} \mathrm{R}$ Youl, S Marriott and T Nabben Landcare in Australia (SILC, 2006).

${ }^{14}$ See, eg, the US Clean Air Act of 1970, 42 USC s 7401 et seq; or the US Federal Water Pollution Control Act, 33 USC ss 1251 et seq.

${ }^{15}$ M Lodge and K Wegrich, Managing Regulation (MacMillan, 2012) 192.

${ }^{16} \mathrm{R}$ Baldwin, M Cove and M Lodge, Understanding Regulation Theory, Strategy and Practice (Oxford University Press, $2^{\text {nd }}$ ed, 2012) 26-27.

${ }^{17}$ For a detailed discussion of the factors that can lead to compliance, refer to the Dutch Ministry of Justice, 'Table of Eleven Causes and Motives that are Relevant to Compliance with Regulation' (2004) <http://www.sam.gov.lv/images/modules/ items/PDF/item_618_NL_The_table_of_Eleven.pdf>. 
compliance is likely to be unrealistic to achieve at manageable cost. ${ }^{18}$ The effectiveness of regulatory strategy can also be assessed in terms of relative costs and benefits. The effectiveness of this approach is dependent on the availability of data and the reasonableness of subjective values assigned. Three important questions to be addressed are: Will the outcome of the analysis lead to benefits exceeding costs or $^{19}$ will a regulation suffer if the costs exceed the benefits in all cases? Is there room for other factors to become part of the decision of the regulation's effectiveness? ${ }^{20}$ Is the regulation accountable politically and to legal standards?

\section{Traditional social science approaches to studying behavioural compliance to laws and regulation}

Various social sciences have used their own disciplinary perspective to study how people respond to community standards and norms that affect their current condition. ${ }^{21}$ Compliance behaviour has been widely studied and the following paragraphs discuss these disciplinary assessments as a basis for identifying similarities and differences, and as a basis for improved approaches to land stewardship.

\section{Political science}

The aim of government should be to achieve progress rather than remain stagnant. If continual progress is to be achieved, government itself must grow and evolve to be able to achieve continued change in light of societal change. ${ }^{22}$ The rise of the administrative state within law making is an example of how elected officials have transferred their authority to non-elected bureaucracies. ${ }^{23}$ To be effective, the administrative state must be dynamic to respond to changing circumstances and situations. In the modern view of political life, the main focus of political science is on power and the role that power plays in struggles between individuals and groups at the international, national, state and local levels. ${ }^{24}$

However, interest in alternative regulatory approaches has grown substantially in political science and public administration over the past decade. As mentioned above, traditional regulatory measures were criticised for being highly legalistic, having high enforcement and compliance costs, and for the intense adversarial relationships they created. ${ }^{25}$

A traditional political science view is that compliance with regulations is not automatic and depends on a range of factors. ${ }^{26}$ For example, compliance can be attributed to a fear of detection and resulting penalties, a feeling of societal pressure to comply, or a sense of civic duty to comply. ${ }^{27}$ Motivations to comply can be 'affirmative' emanating from good intentions and a sense of obligation to comply, ${ }^{28}$ or 'negative' reflecting the fear of the consequences of being found in violation of requirements. Much of the literature on regulatory practices focuses on the deterrent basis for regulatory compliance. Although mandatory regulations are more effective than voluntary approaches alone, combining a voluntary programme with an existing regulatory programme has been recognised to increase compliance. ${ }^{29}$ Groups who can communicate with each other and design their own rules

\footnotetext{
${ }^{18}$ Lodge and Wegrich, above n 15,75.

${ }^{19}$ For example, should the cost effectiveness of a regulation be considered, that is how much cost should reasonably be incurred to bring about the desired outcome, such as to save a human life? Can human life be quantified or monetised in a way that can be applied to regulatory review?

${ }^{20}$ See US Presidential Executive Orders 12291 (17 February 1981) and 13563 (18 January 2011); OECD ten-point reference checklist for regulatory decision making: OECD, 'Improving the Quality of Government Regulations' (C(95)21/Final, OECD/ED, 9 March 1995); OECD, 'Key Elements of Successful Regulatory Impact Analysis' <www.oecd.org/gov/regulatorypolicy/35258511.pdf>.

${ }^{21}$ Adapted from an unpublished manuscript written by Albert Luloff et al (2008).

${ }^{22}$ Matthew Spaulding, 'The Progressive Assault on the Founders' Principles' (2012) [January] First Principles $<$ www.firstprinciplesjournal.com/article>.

${ }^{23}$ Ibid.

${ }^{24}$ Umila Sharma and S K Sharma, Principles and Theory in Political Science (Atlantic Publishers and Distributors, vol 1, 2000$) 6$.

${ }^{25}$ Potoski and Prakash, above n 9, 745.

${ }^{26}$ R Kagan and J Scholz, 'The Criminology of the Corporation and Regulatory Enforcement Strategies in Enforcing Regulations' in K Hawkins and J Thomas (eds), Enforcing Regulation (Boston,1984) 67.

${ }^{27}$ S Winter and P May, 'Motivation for Compliance with Environmental Regulations'(2001) 20 Journal of Policy Analysis 675.

${ }^{28}$ Ibid 677.

${ }^{29}$ P May, 'Regulation and Compliance Motivation: Examining Different Approaches'(2005) 65 Public Administration Review 40.
} 
for dealing with certain types ${ }^{30}$ of problems can achieve substantial improvements over those who do not communicate and have rules imposed upon them.

\section{Sociology}

There are several social theories of law. Systems theory recognises law as a generalised mechanism that operates diffusely in all sectors of society. ${ }^{31}$ The pluralistic sociological approach emphasises law as a part of the general regulatory system in society. Compliance is not a matter of 'objective reality' but rather what is acceptable at a given time. Therefore, a 'zone of compliance' is associated with any regulation and varies according to social perceptions at that time. Determining the level of compliance is complicated by the variation in intensity of enforcement. ${ }^{32}$ Law alone is ill-equipped to bring about the behavioural changes needed to solve existing environmental problems. In the past 30 years, a mix of command and control strategies, design and performance standards, market based measures, prior assessment measures, licensing regulations and land use planning strategies at the state and local level have been applied with varying degrees of success. ${ }^{33}$

\section{Economics}

A basic assumption of traditional economic analysis is that people are forward looking and always act in a rational manner; but this has been criticised as unrealistic when applied to law and regulation. ${ }^{34}$ An economic approach to law addresses both descriptive and evaluative issues. Descriptive issues focus on the rules themselves and their effect on behaviour and outcomes. Evaluative issues address the social desirability of the effects brought about by these rules. ${ }^{35}$

A property right is the right to use a particular item of property in a particular way. ${ }^{36}$ From an economic point of view, property rights promote incentives to work, to make improvements to things that are owned or controlled, and to trade them at the owner's choosing. ${ }^{37} \mathrm{~A}$ use of property may create external effects on others, whether public or private. Bargaining between users and others who are affected will take place in the absence of any rules or regulations that dictate other types of behaviour. ${ }^{38}$ If something becomes a property right because government action extends protection to it, then property rights are subject to change by legislative action that conforms to established constitutional requirements. Regulatory action that impacts on property rights is controversial because its viability depends on authority to impose the restriction and the extent to which the property owner retains a valuable use of the property after regulation is applied.

\section{Law}

To guide behaviour, law must take the form of requirements that people can consult before they act. A legal system requires that citizen behaviour be influenced by internal values that promote compliance most of the time, which is accomplished by as much voluntary compliance with the law as is possible. ${ }^{39}$ Research from law and criminology indicates that deterrence and inducement are the primary determinants of behaviour. ${ }^{40}$ The impacts of crime and recidivism, and reward-punishment studies have been applied to a wide variety of other situations, including landuse and natural resource preservation. Modern legal systems are characterised by formal rationality, systems that use logic and deductive reasoning to derive results from rules, concepts and

${ }^{30}$ E Ostrum, 'The Value-Added of Laboratory Experiments for the Study of institutions and Common Pool Resources' (2006) 61 Journal of Economic Behavior and Organization 162.

${ }^{31}$ S L Roach Anleu, Law and Social Change (Sage Publications, 2000) 40.

32 S Krislov, Compliance and the Law: A Multi-Disciplinary Approach (Sage Publications, 1972).

${ }^{33}$ P Martin and M Verbeek, Sustainability Strategies (Federation Press, 2006).

${ }^{34}$ S Shavell, 'Law and Economics' in Neil J Smelser and Paul B Baltes (eds), International Encyclopedia of the Social and Behavioral Sciences (Elsevier, vol 12, 2001) 8446.

${ }^{35}$ Ibid.

${ }^{36}$ D Needham, 'Property Rights' in Neil J Smelser and Paul B Baltes (eds), International Encyclopedia of the Social and Behavioral Sciences (Elsevier, 2001) 12205, DOI: 10.1016/B0-08-043076-7/04410-7.

${ }^{37}$ Shavell, above $\mathrm{n} 34,8448$.

${ }^{38} \mathrm{R}$ Coase, 'The Problem of Social Cost'(1960) 3 Journal of Lawand Economics 1.

${ }^{39}$ T R Tyler, T R, Compliance/Obedience in N J Smelser and P B Baltes (eds), International Encyclopedia of the Social and Behavioral Sciences (Elsevier, 2001) $2440<\mathrm{http}$ ://www.law.yale.edu/documents/pdf/Faculty/Tyler_Pubs.pdf >.

${ }^{40}$ M Erickson, J Gibbs and G Jensen, 'The Deterrence Doctrine and the Perceived Certainty of Legal Punishments' (1977) 42 American Sociological Review 305. 
principles that can be controlled by the intellect and on which citizens can rely. ${ }^{41}$ According to the classical theory of law, if the punishment for noncompliance is large enough, people will stay within the bounds of cultural rules. ${ }^{42}$

\section{New perspectives from the behavioural sciences}

Given the substantial transaction costs associated with introducing and implementing laws and regulatory mechanisms to change behaviour, governments are becoming increasingly interested in identifying costeffective alternatives. ${ }^{43}$ In particular, there is a growing awareness among policymakers that the successful delivery of policy outcomes requires a more sophisticated understanding of the drivers of human behaviour and, in particular, how behaviour change can best be accomplished. ${ }^{44}$ Indeed, British economist Tim Jackson has suggested 'behavioural change is fast becoming the Holy Grail for sustainable development policy'. ${ }^{45}$ This section explores how principles derived from behavioural science theory can be applied to natural resource management to complement and, in some instances, replace traditional legal approaches. A recurring theme in the behavioural science literature is how governments can get individuals, institutions and related organisations to voluntarily adopt desirable behaviours and practices without creating a complex enforcement structure to create a 'real' threat of punishment should a violation occur.

Many models to predict and explain human behaviour have been generated. Darnton ${ }^{46}$ identified over 60 , which he categorised into two main types: behavioural models and behaviour change models.

\section{Behavioural models}

Behavioural models describe factors that influence specific types of behaviour, and the nature of this influence. These models are particularly useful for identifying the key motivational drivers of behaviour, and the psychological and situational barriers that prevent behaviour from occurring. Many behavioural models assume that behaviours stem from a conscious, deliberate decision-making process involving the systematic evaluation of costs and benefits. These consequentialist models of decision making assume actors evaluate the likely consequences of various courses of action prior to making a choice or decision, and this evaluation serves as a key driver of behaviour. Perhaps the most widely applied consequentialist model of human behaviour within the land stewardship area ${ }^{47}$ is the Theory of Planned Behavior ${ }^{48}$ (TPB). According to TPB, behaviour is preceded by an individual's conscious decision (or reasoned intention) to engage in a specific behaviour (eg, implementing a new set of practices to reduce soil erosion on one's property). People are more likely to develop intentions to engage in a behaviour if: (1) their attitude toward the behaviour is positive, (2) they experience normative pressure from others to engage in the behaviour, and (3) they believe they have the capacity to successfully complete the behaviour. So, for example, landholders may have positive attitudes toward a new soil conservation strategy, and believe their friends and family want them to engage in these activities (positive normative influence). However, they may decide not to implement the new strategy if they do not believe they have sufficient expertise or financial resources to successfully complete the task (low perceived behavioural control).

Although TPB has been very influential in the land stewardship area, it has two important limitations of which practitioners should be aware. First, its main cognitive components (attitudes, social norms, and perceived

\footnotetext{
${ }^{41}$ L Friedman, 'Law: Change and Evolution' in International Encyclopedia of the Social and Behavioral sciences (2002) 8503, DOI: 10.1016/B0-08-043076-7/02904-1.

$42 \mathrm{~J}$ Tedeschi et al, 'Power, Influence and Behavioral Compliance' in S Krislov et al (eds) Compliance and the Law (Sage Publications, 1972) 206.

${ }^{43}$ D Halpern et al, 'Personal Responsibility and Changing Behaviour: The State of Knowledge and Its Implications for Public Policy’(Prime Minister’s Strategy Unit, Cabinet Office, London, 2004).

44 Tyler, above n 40.

45 T Jackson, Motivating Sustainable Consumption: A Review of Evidence on Consumer Behaviour and Behavioural Change. (RES-332-27-0001, Sustainable Development Research Network, Policy Studies Institute, 2005).

${ }^{46}$ A Darnton, GSR Behaviour Change Knowledge Review. Reference report: An Overview of Behaviour Change Models and Their Uses (HMT Publishing Unit, London 2008).

${ }^{47}$ E Wauters et al, Adoption of Soil Conservation Practices in Belgium: An Examination of the Theory of Planned Behavior. (2010) 27 Land Use Policy 86; K S Fielding et al, Integrating Social Identify and the Theory of Planned Behaviour to Explain Decisions to Engage in Sustainable Agricultural Practices (2008) 47British Journal of Social Psychology 23.

48 I Ajzen, 'The Theory of Planned Behavior' (1991) 50 Organizational Behavior and Human Decision Processes 179.
} 
behavioural control) typically explain only 20 to 30 per cent of the variance in behaviour; ${ }^{49}$ that is, TPB fails to account for many of the broader social, cultural and personality factors that influence behaviour. Petraitis, Flay and Miller ${ }^{50}$ developed an expanded model that distinguishes between three main types of influence (social/interpersonal, cultural/attitudinal and intrapersonal) and three levels of influence (ultimate, distal and proximal). These broader frameworks are useful for assisting policy makers and practitioners to adopt a more holistic, systems view of behaviour, and to identify the most promising leverage points to maximise impacts of behaviour change interventions.

A second important limitation of TPB is that it assumes behaviour is the product of a conscious decision-making process. There is considerable evidence from cognitive psychology that human behaviour is driven by habit and other automatised routines. There are also dual process models of cognition ${ }^{51}$ that suggest that human behaviour is guided by two distinct information processing systems: an experiential system that is preconscious, automatic, rapid and intimately tied to emotion; and a rational system that is conscious, slow and analytical. Consequentialist models tend to focus narrowly on the rational system. For example, Hine et al applied dual process theory to decisions related to wood heating, an important source of air pollution in regional Australia. ${ }^{52}$ They found that perceived health risks associated with wood smoke exposure (output from the rational system) was a strong predictor of decisions to switch from wood heating to less polluting alternatives, but only when residents emotional associations towards wood heating (output from the experiential system) were negative. For residents with strong positive emotional associations with wood heating, health risk perceptions were unrelated to switching behaviour. That is, residents who had formed a strong emotional bond with their wood heaters were unwilling to switch to alternative heating systems even when they recognised the substantial negative health impacts associated with their present practices. This suggests that models focusing exclusively on conscious, rational deliberation, such as TPB, are likely to be deficient in explaining behaviour in many contexts. Emotional drivers from the experiential system also need to be taken into account.

The notion that behaviour can be influenced automatically through the experiential system is one of the hallmarks of nudge theory, ${ }^{53}$ which is gaining influence in government and policy-making circles. In their widely cited book on the topic, Thaler and Sunstein argue that the traditional economic view of humans as deliberative rational decision makers (homo-economicus) is fundamentally flawed, and policy makers can elicit (often automatic) socially desirable responses by simply manipulating the choices available. For example, to increase organ donation, policy makers could shift the default option from 'opt-in' to 'opt-out'. Thus, by doing nothing, individuals behave in a manner that benefits society. They describe this approach as an example of libertarian paternalism given that policy makers are not legally compelling citizens to behave in a specific way, but are increasing the probability of socially responsible behaviour by modifying the context in which choices and decisions are being made.

In summary, there are a host of behavioural models that can inform land-stewardship practice. The most common model is TPB, which has proven to be very useful in helping to understand and predict land management practices in a range of settings. However, it is important to recognise that this widely applied model has inherent limitations, and that researchers and practitioners in the land-stewardship space should also consider other models and frameworks that incorporate a broader range of drivers and barriers, and explicitly distinguish between conscious and unconscious decision processes. Following are several promising examples of behaviour change that describe the processes by which individuals alter their behaviour over time.

${ }^{49}$ C Armitage and M Conner, 'Efficacy of the Theory of Planned Behaviour: Ameta-Analytic Review (2001) 40 British Journal of Social Psychology 471.

$50 \mathrm{~J}$ Petraitis, B R Flay and T Q Miller, 'Reviewing Theories of Adolescent Substance Use: Organizing Pieces of the Puzzle' (1995) 117 Psychological Bulletin 67, DOI: 10.1027/0033-2909.117.1.67.

${ }^{51}$ S Epstein, Integration of the Cognitive and the Psychodynamic Unconscious (1994) 49 American Psychologis 709; J St B T Evans, and K Frankish, In Two Minds: Dual Processes and Beyond (Oxford University Press, 2009); D Kahneman, Thinking, Fast and Slow (Penguin, 2011).

${ }^{52}$ D W Hine et al, 'Keeping the Home Fires Burning: The Affect Heuristic and Wood Smoke Pollution' (2007) 27(1) Journal of Environmental Psychology 26.

${ }^{53} \mathrm{R}$ H Thaler and C R Sunstein, Nudge: Improving Decisions about Health, Wealth, and Happiness (Yale University Press, 2008). 


\section{Behaviour change models}

To develop effective policy, it is not sufficient to identify key drivers and barriers of behaviour - as behavioural models attempt to do. The processes by which behaviour actually changes must also be understood.$^{54}$ Perhaps the most influential model of behavioural change is the transtheoretical model, ${ }^{55}$ which has been used extensively in health psychology. According to this model, the behaviour change process comprises five distinct stages: pre-contemplation (not planning to change), contemplation (intending to change within the next six months), preparation (intending to change soon and preparing for change), action (currently going through the change process), and maintenance (sustaining change for six months or more). There is also the possibility of relapse, in which case the individual fails to maintain the new behaviour and moves back to an earlier stage in the change process. The transtheoretical model highlights the importance of tailoring policy interventions such that they take into account variation in where individuals reside in the overall change process. The model suggests that different behavioural drivers and barriers may be operating at different stages, and that different types of interventions may be required to move individuals from, for example, pre-contemplation to contemplation, then from preparation to action.

This notion of segmenting populations into homogenous subgroups based on current beliefs and behaviour plays lies at the heart of social marketing. Whereas the primary aims in traditional marketing are to identify new markets, increase sales and maximise profit, the main goal in social marketing is to influence behaviours that benefit the target audience and society as a whole. Social marketing has been used extensively in health psychology for designing engagement and behaviour change programmes associated with increasing physical activity, quitting smoking, moderating alcohol use and combating obesity, and is currently attracting considerable attention amongst researchers and practitioners working in the areas of climate change and environmental sustainability. ${ }^{56}$ Supporting the general efficacy of this approach, a recent meta-analysis by Noar and his colleagues ${ }^{57}$ indicated that health messages tailored and targeted to audience segments achieve significantly greater behavioural change than generalised, non-tailored messages. The size of the effect was quite modest but, as Hine et $\mathrm{al}^{58}$ note in their review of the audience segmentation literature, small effects applied to large populations can produce substantial on-the-ground impacts.

\section{Behaviour change techniques}

In addition to theoretical models of behaviour and behaviour change, behavioural scientists have also developed an extensive list of behaviour change techniques. In their excellent overview of the topic, Abraham and Michie ${ }^{59}$ developed a typology of 28 behaviour change techniques (eg, incentives, prompts, modelling, performance feedback, persuasion), each linked back to specific theories of behaviour. A key idea underlying this typology is that behaviour is a complex construct, and that different behaviour change techniques are required for different types of behaviour. For example, incentives and appeals to reason may prove to be effective in influencing behaviour that is under conscious control of the decision maker, but may be less suitable for changing habitual and automatic behaviours.

${ }^{54}$ A Darnton, GSR Behaviour Change Knowledge Review. Practical Guide: An Overview of Behaviour Change Models and Their Uses (HMT Publishing Unit, 2008).

55 J O Prochaska, C C DiClemente and J C Norcross, 'In Search of How People Change: Applications to Addictive Behaviors' (1992) 47(9) American Psychology 1102.

${ }^{56}$ D W Hine et al, 'Identifying Climate Change Interpretive Communities in a Large Australian Sample' (2013) 36 Journal of Environmental Psychology 229.

${ }^{57}$ S M Noar, C N Benac and M S Harris, 'Does Tailoring Matter: Meta-Analytic Review of Print Health Behavior Change Interventions' (2007) 133(4) Psychological Bulletin 673.

${ }^{58}$ D W Hine et al, 'Audience Segmentation and Climate Change Communication: Conceptual and Methodological Consideratlons' (2014) 5 Wiley Interdisciplinary Reviews - Climate Change 441.

${ }^{59}$ C Abraham and S Michie, 'A Taxonomy of Behaviour Change Techniques Used in Interventions' (2008) 27 Health Psychology, 379. 


\section{Integrative frameworks for behaviour change interventions}

Several authors have proposed broader frameworks for embedding behavioural science theory into policy development and 'on-the-ground' behaviour change interventions. ${ }^{60}$ Darnton's Action Research Framework represents a good exemplar about how this can be done. The framework consists of eight general principles:

1. Identify audience sub-groups, behaviours to be changed and outcomes desired.

2. Select appropriate behavioural and behaviour change models and generate a shortlist of influence factors.

3. Design a draft behaviour change strategy with clear, achievable aims and incorporate the most promising influence factors.

4. Identify appropriate intervention techniques matched to the specific stage of change individuals have reached and recognising that different techniques may be required to move individuals through different stages.

5. Engage the target audience for the intervention to improve the approach and gain understanding of the target behaviour sort and influence factors from their perspective.

6. Develop a prototype intervention in collaboration with the target audience. Pilot test the intervention.

7. Implement the final intervention and evaluate its effects using quantitative and qualitative methods.

8. Provide feedback as an on-going, iterative learning process.

These types of integrative frameworks can provide practitioners with practical step-by-step guides that can substantially increase the likelihood that their interventions will be successful.

\section{An assessment of land stewardship in practice}

Three examples provide a practical perspective as a basis for the development of new approaches to reducing conflict and improving the role of farmers as land stewards and, in particular, to emphasise the importance of joint approaches to developing solutions and the need for improved communication between regulators and the regulated.

\section{Sea eagles and geese versus farmers in Scotland}

On the islands of Islay and Mull, in the Inner Hebrides, Scotland, UK there has been growing conflict between land holders and government conservation bodies about the effect of birds on livestock and on crops to the extent that farmers have sought compensation for the damage done. ${ }^{61}$ Traditional approaches have been based on a calculation of compensation to the farmers for loss of income. On Mull, this was based on the value of the lambs claimed to have been killed by white tailed eagles. On Islay, it was based on costs from the loss of spring grazing for cattle and sheep because of heavy grazing by geese over wintering on Islay before their return to their summer breeding grounds in the Arctic. This traditional approach to seeking a resolution to the conflict between farming and nature conservation interests was very costly to the taxpayer, reinforced the stand-off between the protagonists and failed to provide an enduring accommodation between the two sets of interest. ${ }^{62}$

The dirigiste approach operated by the government ministry demanded the traditional solution. However, the state nature agency wished to find the basis for a new modus operandii between the parties which would recognise the legitimacy of both agents, result in active engagement by the farmers in providing a solution and provide a more cost effective outcome. In both cases, this required setting aside the imposed views from central government and seeking options from the farmers. In both the Islay and Mull cases, the solution lay in giving a specific role to the farmers to participate in managing the conflict situation. In the case of white tailed eagle predation on lambs, farmers were paid for monitoring the contents of the eagle nests to identify the food sources from the bones found, and for managing the sheep flock more actively by placing the females, prior to lambing, in fields that the eagles rarely visited. The amount paid to the farmers for this positive activity was

\footnotetext{
${ }^{60}$ Darnton, Above n 54; G Gardner and P Stern, Environmental Problems and Human Behaviour (Pearson, $2^{\text {nd }}$ ed, 2002); D Mckenzie-Mohr, Fostering Sustainable Behavior: An Introduction to Community Based Social Marketing (New Society Publishers, 3rd ed, 2011).

${ }^{61}$ Scottish Natural Heritage, ‘Annual Report’ (Battleby, Scotland, 1995).

${ }^{62}$ R Crofts, Resolving Conflicts in Resources Management <rogercrofts.net>; J M Baxter and C A Galbratih (eds), Species Management: Challenges and Solutions for the $21^{\text {st }}$ Century (The Natural Heritage of Scotland) (Edinburgh, The Stationary Office, 2010).
} 
only half of the compensatory payment that would have been made under the traditional approach. In the case of Islay, local people were paid for scaring the geese from fields needed for spring grazing of livestock, farmers were paid for re-seeding fields and for establishing refuge areas where the geese could feed without being disturbed. Despite suspicions lingering about this approach, after a relatively short time, two-to-three years in most cases, the farmers accepted the innovative approach.

Evaluations of the effectiveness of the measures carried out independently for the Scottish Government ${ }^{63}$ suggest that allowing for local variations in schemes to satisfy local needs and circumstances is not welcomed by central institutions; a sure sign that the political will for delegating arrangements to a partnership of local stakeholders is not yet accepted by central government decision makers and assessors.

The main outcomes of these more interactive approaches are: lower cost, greater effectiveness, and engagement of farmers as part of the solution rather than part of the problem. The dynamic has changed and more participative approaches might have a greater chance of developing partnerships with a view to achieving greater harmony and reducing conflict.

The motivation for change in these cases came, perhaps surprisingly, from a government agency that believed traditional approaches bred conflict. Traditionalists in the government ministries were not immediately persuaded and it took some bravado on the part of senior members of the government agency and some creative thinking by their colleagues on the ground in devising new approaches before the battle between agricultural and nature bureaucracies took a positive step forward.

The lessons learned in these two Scottish examples - such as engagement of those to whom policy applies, respect for their opinion, and allowing flexible approaches to problem solving - have been employed elsewhere in the country to the resolution of the management of internationally important wetland ecosystems with actual and potential high carbon storage to aid meeting climate change mitigation targets. ${ }^{64}$

\section{Environmental conditionality in EU agriculture}

Experience of seeking to change the basis of regulation and partnership in the European farming system under the Common Agricultural Policy (EU CAP) is rather less positive. This highly complex bureaucratic system: baffles and confounds farmers and even their technical advisers; blocks innovation; and fuels conflict between farmers and environmental interests. Basically, attempts to introduce more broad-based approaches which recognise, reward and regulate farmer's roles as stewards of the land and water resources - as well as producers of high quality food and bio-safety guardians - in return for receipt of substantial funds from public sources via the EU, have proved to be difficult. The real politique results in farmers' interests being given preference over societal interests in the guardianship of natural resources of soil and water, or environmental interests for halting the loss of biodiversity and improving the quality of the ecosystem services provided.

The recent negotiations leading to agreement on the next round of the EU CAP are a case in point. The original proposals for a new policy set out by EU bureaucrats ${ }^{65}$ were widely praised among the environmental movement as creative and far reaching and broke with the traditional compensation mode ${ }^{66}$ However, during the course of the next two years the traditionalist voices of farmers, and especially their leaders in key countries where they carry great political weight - such as France, Germany and Poland - gradually whittled down the original proposals to a set, which reflected more on the political dynamic of the lobby groups than the more enlightened forces ${ }^{67}$ The result will mean remaining high levels of subsidies, heavy bureaucracy for the development of national plans and scrutiny of their implementation, heavy bureaucracy for farmers in filing

${ }^{63}$ Scottish Government, Review of Goose Management Policy in Scotland (2010) <www.scotland.gov.uk/Publications/2011/02/03083950/21>.

${ }^{64} \mathrm{~J}$ M Milner and S M Redpath, 'Building an Evidence Base for M̄anaging Species Conflict in Scotland' (Scottish Natural Heritage Commissioned Report No 611) <http://www.snh.gov.uk/publications-data-and-research/publications/search-thecatalogue/publication-detail/?id=2030>.

${ }^{65}$ European Commission, 'The CAP Towards 2020: Meeting the Food, Natural Resources and Territorial Challenges of the Future' (COM 672 final, Communication from the Commission to the Council, the European Parliament, the Economic and Social Committee and the Committee of the Regions COM, 2010).

${ }^{66}$ A Caserta et al, Re: Inter-Service Consultation on CAP Reform: Concerns That Greening of the CAP Is Being Jeopardised and Losing Environmental Focus (Brussels, 2011).

${ }^{67}$ European Commission, 'CAP Reform - An Explanation of the Main Elements' (EU Memo/13/621, 2013). 
returns, and, most significantly in the context of this paper, no agreement between nature and farming interests and therefore no real social license.

\section{Soil conservation and land restoration in Iceland}

Over the last century, Iceland has evolved its approach to the stabilisation of the land and the restoration of usable land for agriculture. The following is drawn from a more detailed account by Crofts. ${ }^{68}$

For most of the century, the Soil Conservation Service of Iceland (SCSI) took a technocratic approach based on adaptation of ideas from: other countries - especially Denmark and later the US - local experimentation; and the experience of the agriculturalists employed by the organisation. In effect, it was a dirigiste approach driven by the application of scientific and technical knowledge to the land with very limited engagement with farmers. One manifestation of this approach was the use of aircraft to sow seed and spread fertiliser from the air, a technique adopted from New Zealand. Farmers were rarely directly involved in managing their land for soil conservation and land restoration. The breakthrough came from the late 1980s with consideration of an enhanced role for farmers. Observation of the effectiveness of farmer engagement, developed originally in Australia under the Landcare programme, was considered to have benefits for Iceland by changing the paradigm from the dirigiste approach to a partnership approach. The programme developed was called Farmers Heal the Land. The title is resonant of the new approach with direct engagement of farmers as stewards in the delivery of soil conservation and land restoration. To succeed, the programme required new skills in the SCSI based on negotiation and partnership working, the practice of knowledge transfer from the experts in the organisation to their colleagues working in the field and from them to the farmer partners, and an ability to learn from farmers themselves.

A paradigm shift was required to achieve the changes needed. This came not from the government ministry but from the leadership of the SCSI. Change required an ability by the leaders to recognise that old approaches are not always the most successful; that lessons can be learned from other countries and applied to fit local circumstances; and that the original skills and competences of staff are not adequate to address these new approaches. However, in the complex administrative structures and policy web of agriculture in Iceland, there remained a lack of political will to change the fundamental policies which encouraged over-grazing of the land, especially by sheep, and a failure to reward stewardship of environmental resources to the benefit of the farmers' capital assets and to civil society as a whole.

Three main obstacles to change have been persistent in Iceland. First, agricultural policy rested on a traditional paradigm of large numbers of animals with the farmer being rewarded per head of sheep flock. Despite arguments from the SCSI, backed with evidence that a reduction in sheep numbers was needed to reduce soil erosion in Iceland, sheep numbers were only reduced because of overproduction of sheep meat in relation to market demand. The resultant impacts on soil conservation and land restoration were incidental. No policy ideas to stimulate better stewardship of the land have emanated from the agriculture ministry despite the fact that it is the sponsor of the SCSI and funder of its work (until this was moved to the Ministry of the Environment in 2011). Again the lobby power of the farmers and the support they were given from successive Ministers of Agriculture, as in the EU, resulted in lack of an integrated policy for land stewardship.

Second, and related to the first, is that the allocation of resources to soil conservation and land restoration are minute when compared with traditional subsidy to agriculture. The SCSI budget is only 4 per cent of the agricultural support budget; grant levels for forestry, for example, are twice as high as for land restoration.

The other obstacle has been the unwillingness of farmers to change their practices Traditional mindsets proved difficult for the SCSI to transform into more modern integrated approaches. Almost two thirds of the Icelandic farmers are not participants in the Farmers Heal the Land programme. More fundamentally, the grazing of the Highland Commons (common land in the highlands owned jointly by farmers in lowland parishes and grazed during the short summer) is highly problematic. The nutrition resources of these commons is generally very low, their vulnerability to overgrazing very high with the result that over grazing and long-term damage to the vegetation cover is a frequent occurrence. Given the long natural recovery time in these arctic areas, the value of the grazing diminishes. Yet farmers still insist on their rights to graze these areas and maintain the

\footnotetext{
${ }^{68}$ R Crofts, Healing the Land: The Story of Land Reclamation and Soil Conservation in Iceland (Soil Conservation Service of Iceland, 2011).
} 
associated traditions of taking the stock out and bringing them back in - a male activity that, despite diminishing sheep numbers, is fiercely guarded by the farming community. A recent example (2013) where the SCSI strongly recommended against restarting grazing on a badly eroded area has been ignored by local farmers and not supported by the Minister for Agriculture and the Environment. No sanctions are available to be imposed and no changes in agricultural policy are foreshadowed that would be able to tackle this intransigence. Scientific analysis has, on the other hand, recommended that grazing be discontinued from many of these highland commons.

\section{Developing the new paradigm for land stewardship}

From the foregoing review of the social science literature and the three case studies, what general conclusions can be draw as a basis for improving policy and practice?

A legal approach implies a social compact between society and government implemented through regulation. It enables the identification of undesirable behaviour and what changes are needed to bring about socially desirable behaviour. But, to be effective, regulation needs to be efficient, socially fair and transparent, and based on a combination of deterrence and inducement. However, regulation alone is not sufficient because it cannot readily cope with human behaviour traits and resistance to change. Given social psychological and behavioural science models provide a deeper understanding of human behaviours in all their diversity and complexity, their application can inform the development of new approaches to policy making that are more effectively targeted and more likely to achieve the desired outcomes. Models based on emotional - rather than rational, drivers from an experiential system are usually significant in examining behavourial change. Although it is valuable to embed behavioural and behaviour change models in the policy development and implementation process, these models should not be treated as templates that can be inflexibly applied to any policy issue or target group of people. Each policy issue and each target group of people are unique and both must be thoroughly understood prior to developing and implementing a behaviour change strategy. Models can help guide thinking about intervention design but they are not 'ready-made' solutions in themselves. Consideration must be given to the type of situation in which behaviour change strategies could best be applied. Using integrative approaches, such as Darnton's Action Research Framework, ${ }^{69}$ will help to identity the necessary steps, including processes of engagement of the key target audiences, the behaviour changes sought and the outcomes desired.

The experiences from the three case studies demonstrate that for changes in the paradigm to occur requires some fundamental shifts in the attitudes of the key stakeholders, especially those who determine policies and practices and those who implement them on the ground. Top-down approaches do not work as effectively as more sophisticated approaches involving all stakeholders in assessing options and providing solutions, and which accept the legitimacy of other stakeholders' rights to participate as well as the practical knowledge which they can contribute. But the bureaucrats and ministers in the agricultural ministries, who have an in-built philosophy of being the farmers' friend rather than an advocate of change and regulator of the sector, are averse to change. Change can only come from the willingness of politicians in positions of power to accept that the current situation is not creating sufficient benefits to satisfy the needs and aspirations of society at an acceptable cost and that change is necessary. To consolidate such a change in mindset does, however, require changes in the behaviour of all those involved. For example, the technocrats need to shift towards a communicative approach based on knowledge exchange rather than merely knowledge transfer. The policy advisers need to recognise that novel solutions can be the most effective way forward and be prepared to make fundamental changes in policy objectives and allied allocation of resources to support more integrated, multiobjective programmes. Participative approaches clearly work provided there are willing partners, but without significant incentives and without any regulatory control there can be no guarantee that the majority of farmers are willing to participate. Learning from policy and practice in other countries can provide new ideas tailored to local circumstances if the audience is open to learning.

The clear message from our analysis of the literature and the case studies is that top down approaches based purely on regulations do not work. There is plenty of evidence from previous work and from the case studies quoted for a more bi-partisan mixture of top-down and bottom-up approaches that must be operated in a

${ }^{69}$ Darnton (2008a), above n 54. 
coherent manner and making sure that policies and practices share common aims and do meet in the middle! Crucial to making this approach workable are a number of ingredients that, together, are styled 'the new paradigm for land stewardship by farmers on behalf of society':

1. Recognise the varying behaviours of all involved. A new approach to how farmers act as stewards in caring for the natural resources of the land is needed to redress the continuing degradation of the land and to ensure that societies' needs and requirements, now and in the future, are adequately catered for, whilst maintaining the natural productive capacity of the land. It should be informed by the lessons learned from the science of human behaviour and from practical experience. A greater understanding of the current behaviours and how they react to requirements to change behaviour of the key stakeholders is essential if change to meet broader societal objectives is to be achieved. Success depends on using the experience of behavioural and behavioural change models, the widest range of stakeholders (eg, farmers, children and youth, indigenous communities, scientists and technologists, business and industry etc.) as developers and peer reviewers of new approaches.

2. Use an inclusive process to develop solutions. Policy development processes and assumptions need to be more inclusive of the interests they affect. If behaviour is to be affected in a desired way, policy developers must take into account and engage as widely as possible those whose interests will be affected by the policy. The strategy of convening a panel of agency or industry experts to draft regulations which are put before the public for 'review and comment' should be revised to reverse the process so public engagement occurs before regulations are drafted rather than after. Law and regulatory development should begin with a comprehensive analysis of the behaviour of those who are part of the problem being addressed. In what ways has the behaviour of these people led to the problem? How can that behaviour be changed to accomplish a desired outcome? Once current behaviour is understood, law and policy developers should address the behavioural interventions that can achieve the desired outcome. Once these interventions are identified, policy developers can assess the impact these interventions will have, and how these new processes will impact time and resources.

3. Develop an ethical charter for resource use and management. New contracts between society and farmers should be the fundamental component of the new paradigm based on redefining the role of farmers as natural resource managers and food producers: what is commonly called 'the public good argument'. This could be done internationally by adopting an ethical approach: a soils and society charter - 'soils for the sustainable health of our world'. But it also needs to provide contracts that are meaningful to society and to the farmers and contain a mixture of regulation and incentive implemented in a stepwise manner to seek to change behaviours.

4. Use multifaceted approaches to induce positive attitude change. Changing mind-sets is fundamental but takes time and patience. How does a regulatory agency tasked with addressing a problem motivate the regulated community to participate (fully and effectively) to accomplish the result it was assigned? How do traditionalists become modernists in terms of production practices that achieve desired results? The answer lies in a combination of approaches embracing economic incentives, peer pressure, application of behavioural change experience in practice, social marketing, and education.

5. Develop policy to reflect a blend of local reality and high-level imperatives. Allowing policy flexibility to consider local impacts of policy mandates is necessary. A more flexible approach than a single 'one size fits all approach' is justified in many circumstances. It is based on a 'performance standard policy' (this is the goal you are to achieve and it is your obligation to find a way to achieve it), rather than a 'design standard policy' based on a set of tools and assumptions that must be applied whatever the circumstances.

6. Ensure that all policy has multiple objectives. Implementing the multi-objective approach. Stakeholders at local, regional and national levels must agree that land use is a multi-objective activity embracing ecosystem management and delivering environmental services, disaster prevention, poverty alleviation and producing food, and is a fundamental objective in local, national, regional and global approaches.

7. Exchange knowledge on an equal basis between all parties. Mechanisms for knowledge exchange should be relevant and accessible to target groups, not internationally peer reviewed journals or 
scientific speak, provided by skilled and knowledgeable communicators and modern communication modes, and recognising indigenous knowledge.

In summary, changing behaviour towards the management of land resources requires a more subtle and informed approach than has often been used in the past. The way policy is developed and the people who play a part in that development must be open to new ways of fulfilling their roles. Traditional solutions developed by policy advisers and implemented by government ministers in a dirigiste manner rarely have the desired effect because they do not take into account the perspectives and behaviours of the key stakeholders and ignore the lessons learnt from research on motivation and practice on the ground. The review of literature presented demonstrates that, irrespective of which academic discipline addresses the issue of how to change behaviour - economics, law, sociology, politics and psychology - one fundamental point emerges. In short, behaviour change is brought about by more interactive processes to define the present position, agree on the desired outcomes and the mechanisms (regulation and deterrence, financial and non-financial incentives) needed to get there, bearing in mind gradual rather than accelerated processes are likely to be more successful. If lawmakers and agency officials are sincerely committed to achieving better results through compliance based on behavioural modification, then the upfront costs to engage the public before laws and regulations are drafted will be worth the investment. 